\title{
Direct targeting of MAPK8IP1 by miR-10a-5p is a major mechanism for gastric cancer metastasis
}

\author{
YAOYONG LU*, GANBAO WEI*, LIANGBO LIU*, YICHAO MO*, QINGSHENG CHEN, \\ LUFEI XU, RONGWEI LIAO, DEHAO ZENG and KUNQIANG ZHANG
}

Department of Radiation Oncology, Gaozhou People's Hospital, Gaozhou, Guangdong 525200, P.R. China

Received June 20, 2015; Accepted October 24, 2016

DOI: $10.3892 / \mathrm{ol} .2016 .5544$

\begin{abstract}
MicroRNA (miRNA) are endogenous non-coding RNAs that suppress gene expression at the transcriptional, post-transcriptional or translational level by targeting the 3'-UTRs of specific mRNAs. miR-10a has been frequently reported to be aberrantly overexpressed in human tumors. In gastric cancer (GC), miR-10a has an important role in the metastasis from primary GC to lymph nodes. However, the role and relevant pathways of miR-10a in GC metastasis remain largely unknown. The present study was performed using $41 \mathrm{GC}$ and 20 normal gastric mucosa tissues. Reverse transcription-quantitative polymerase chain reaction (RT-qPCR) analysis demonstrated that MAPK8IP1 was significant downregulated in GC tissue. A statistically significant inverse correlation was detected between miR-10a and MAPK8IP1 mRNA expression levels in GC specimens. Luciferase reporter assay and qPCR results suggested that MAPK8IP1 was a direct target of miR-10a in GC cells. Matrigel invasion assay and wound-healing assay results showed that MAPK8IP1 overexpression rescued the increased migration ability of miR-10a effectors in MKN45 cells. Furthermore, the underlying mechanism of miR-10a functions in GC was explored. The findings indicated that miR-10a-5p directly targets MAPK8IP1, as a major mechanism for gastric cancer metastasis. The results of the present study suggested that miR-10a may be a potential target for the treatment of GC in the future.
\end{abstract}

\section{Introduction}

Gastric cancer (GC) ranks as the second leading cause of cancer-associated mortality worldwide, accounting for

Correspondence to: Dr Kunqiang Zhang or Dr Rongwei Liao, Department of Radiation Oncology, Building No.6, Gaozhou People's Hospital, No. 89 Xiguan Road, Gaozhou, Guangdong 525200, P.R. China

E-mail: kunqiang_zhang@yeah.net

E-mail:mmgzzkq@21cn.com

${ }^{*}$ Contributed equally

Key words: mitogen-activated protein kinase 8IP1, miR-10a-5p, gastric cancer, metastasis, mitogen-activated protein kinase signaling $\sim 1,000,000$ deaths worldwide per year and $\sim 10 \%$ of newly diagnosed cancer incidence (1). Common features of GC include invasive progression and a high frequency of metastasis to lymph nodes (2-4). The malignant potential of cancer is manifested in the ability of tumor cells to form metastases in distant organs (5). Various steps in the complex metastatic process are associated with the mitogen-activated protein kinase (MAPK) pathways, which are activated by mitogens and have been found to be upregulated in human $\mathrm{GC}(6,7)$. MAPK8IP1 is able to interact with dual leucine zipper-bearing kinase/mixed-lineage kinases, MKK7 and c-Jun N-terminal kinases MAPKs, act as a negative regulator of MAPK activity $(8,9)$.

Data from several studies have shown that various genetic alterations induce tumorigenesis and the progression of GC (10). MicroRNA (miRNA) are endogenous non-coding RNAs that suppress gene expression at the transcriptional, post-transcriptional or translational level by targeting the 3'-UTRs of specific mRNAs $(11,12)$. Aberrant miRNA expression has frequently been reported in various tumors, including lung cancer $(13,14)$, breast cancer $(15)$, colon cancer (16) and leukemia (17), indicating that they have emerged as important regulators of human malignancy.

miR-10a has been reported to be aberrantly overexpressed in human tumors $(18,19)$. For example, miR-10a is overexpressed in human pancreatic cancer and is associated with its invasiveness, which occurs, in part, via the suppression of the HOXA1 gene (20). Retinoic acid receptor antagonists inhibit miR-10a expression and block metastatic behavior of pancreatic cancer (21). Moreover, therapeutic silencing of miR-10b has been shown to inhibit metastasis in a mouse mammary tumor model (22). In GC, miR-10a has an important role in metastasis from primary GC to the lymph nodes (23). However, the role and relevant pathways of miR-10a in GC metastasis remain unknown.

The present study was performed using $41 \mathrm{GC}$ and 20 normal gastric mucosa tissues. Reverse transcription quantitative polymerase chain reaction (RT-qPCR) analysis was used to assess the expression levels of MAPK8IP1 in GC tissue, the results revealed significantly downregulated MAPK8IP1 in GC tissue. Furthermore, a statistically significant inverse correlation was observed between miR-10a and MAPK8IP1 mRNA expression levels in GC specimens. Luciferase reporter assay and qPCR results suggested that MAPK8IP1 was a direct 
Table I. Summary of the primers used in the reverse transcription-quantitative polymerase chain reaction.

\begin{tabular}{lll}
\hline Gene & \multicolumn{1}{c}{ Forward primer $\left(5^{\prime}-3^{\prime}\right)$} & Reverse primer $\left(5^{\prime}-3^{\prime}\right)$ \\
\hline MAPK8IP1 & ATCGCTTCGCCTCCCAATTT & ATCTCCGAGAGGTCTTCATCC \\
$\beta$-catenin & AAAGCGGCTGTTAGTCACTGG & CGAGTCATTGCATACTGTCCAT \\
Snail & TCGGAAGCCTAACTACAGCGA & AGATGAGCATTGGCAGCGAG \\
Fibronectin & CGGTGGCTGTCAGTCAAAG & AAACCTCGGCTTCCTCCATAA \\
Vimentin & GACGCCATCAACACCGAGTT & CTTTGTCGTTGGTTAGCTGGT \\
PTEN & TGGATTCGACTTAGACTTGACCT & GGTGGGTTATGGTCTTCAAAAGG \\
Akt & AGCGACGTGGCTATTGTGAAG & GCCATCATTCTTGAGGAGGAAGT \\
N-cadherin & AGCCAACCTTAACTGAGGAGT & GGCAAGTTGATTGGAGGGATG \\
E-cadherin & CGAGAGCTACACGTTCACGG & GGGTGTCGAGGGAAAAATAGG \\
GAPDH & GGAGCGAGATCCCTCCAAAAT & GGCTGTTGTCATACTTCTCATGG
\end{tabular}

MAPK, mitogen-activated protein kinase; PTEN, phosphatase and tensin homolog.

target of miR-10a in GC cells. Matrigel invasion assay and wound-healing assay findings showed that MAPK8IP1 overexpression rescued the increased migration ability of miR-10a effectors in MKN45 cells. Finally, the underlying mechanism of miR-10a functions in GC were explored.

\section{Materials and methods}

Ethics statement. For the use of these clinical materials for research purposes, prior written informed consent was obtained from all of the patients and ethical approval was granted by the Ethics Committees of Gaozhou People's Hospital (Gaozhou, China).

Cell culture and tissue collection. MKN45 and HNE-1 human GC cell lines (Cancer Research Institute, Southern Medical University, Guangzhou, China) were cultured in Dulbecco's modified Eagle's medium (DMEM) supplemented with $10 \%$ fetal calf serum (both from Invitrogen; Thermo Fisher Scientific, Inc., Waltham, MA, USA) at $37^{\circ} \mathrm{C}$ in a $5 \% \mathrm{CO}_{2}$ incubator. In total, $41 \mathrm{GC}$ specimens and 20 non-cancerous control normal gastric mucosa tissues were obtained at the time of diagnosis before any therapy was administered at Gaozhou People's Hospital. In 41 cases, there were 33 males and 8 females with ages ranging from 38 to 78 years (mean age, 56.7 years). All specimens had a confirmed pathological diagnosis and were staged according to the 2009 UICC-TNM Classification of Malignant Tumors (24).

RNA extraction and RT- $q P C R$. Total RNA was extracted from MKN45 cells with TRIzol reagent (Sigma-Aldrich; Merck Millipore, Darmstadt, Germany). DNase (1 U/ $\mu$ g RNA) was applied with thermal denaturation at $75^{\circ} \mathrm{C}$ for $5 \mathrm{~min}$ to remove genomic DNA. RNA ( $3 \mu \mathrm{g})$ was reverse transcribed into cDNA using a High-Capacity cDNA Reverse Transcription kit (Applied Biosystems; Thermo Fisher Scientific, Inc.). The RT mixture contained 2X RT Master Mix in a final volume of $10 \mu \mathrm{l}$, including $2.0 \mu \mathrm{l} 10 \mathrm{X}$ RT Buffer, $0.8 \mu \mathrm{l} 25 \mathrm{X}$ dNTP Mix (100 mM), 2.0 $\mu \mathrm{l}$ 10X RT Random Primers, $1.0 \mu \mathrm{l}$ MultiScribe $^{\mathrm{TM}}$ Reverse Transcriptase, $1.0 \mu \mathrm{l}$ RNase inhibitor and
$3.2 \mu \mathrm{l}$ nuclease-free $\mathrm{H}_{2} \mathrm{O}$. Total RNA was added to the $2 \mathrm{X}$ RT Master Mix to create a $1 \mathrm{X}$ mix, and RT was performed in a thermal cycler $\left(25^{\circ} \mathrm{C}\right.$ for $10 \mathrm{~min}, 37^{\circ} \mathrm{C}$ for $120 \mathrm{~min}$, and $85^{\circ} \mathrm{C}$ for $5 \mathrm{~min}$ ). RT-qPCR analysis of mRNAs of MAPK8IP1, $\beta$-catenin, Snail, fibronectin, vimentin, phosphatase and tensin homolog (PTEN), Akt, N-cadherin, E-cadherin and GAPDH (internal standard) were performed on a StepOne ${ }^{\text {TM }}$ Real-time PCR system using Power SYBR ${ }^{\circledR}$ Green PCR Master mix (both Applied Biosystems; Thermo Fisher Scientific, Inc.) in a final volume of $20 \mu \mathrm{l}$, comprising $100 \mathrm{ng}$ cDNA, $10 \mu \mathrm{l}$ master mix, $1 \mu \mathrm{l} \mathrm{ROX}$ and $0.4 \mathrm{pmol} / \mu \mathrm{l}$ of each primer. Thermal cycling conditions included an initial denaturation for $1 \mathrm{~min}$ at $95^{\circ} \mathrm{C}$, followed by 40 cycles consisting of an annealing step at $95^{\circ} \mathrm{C}$ for $5 \mathrm{sec}$ and an extension step at $60^{\circ} \mathrm{C}$ for $20 \mathrm{sec}$. Each sample was analyzed in triplicate. The primer sequences used for PCR are shown in Table I. The relative expression levels of the genes were calculated according to the $2^{-\Delta \Delta \mathrm{Cq}}$ method. Results were analyzed using Applied Biosystems 7500 system software v1.4.0.

Wound-healing assay. Cell migration was assessed using scratch-healing assays. Briefly, MKN45 cells stably transfected with miR10a-5p and NC were cultured in 6-well plates ( $5 \times 10^{5}$ per well). When the cells grew to $90 \%$ confluence, three scratch wounds across each well were formed using a P-200 pipette tip. Fresh DMEM supplemented with reduced (5\%) fetal bovine serum (FBS) was added, and the wound-closing procedure was observed for $24 \mathrm{~h}$. Images were captured at 0 , 12 and $24 \mathrm{~h}$, respectively.

Invasion assay. For the invasion assay, $1 \times 10^{5}$ cells were seeded in $100 \mathrm{ml}$ DMEM on the top of polyethylene terephthalate membranes coated with Matrigel $(1.5 \mathrm{mg} / \mathrm{ml}$; BD Biosciences Inc., San Jose, CA, USA) within Transwell cell culture inserts (24-well inserts; pore size, $8 \mathrm{~mm}$; Corning Life Sciences, Corning, NY, USA). The bottom chamber was filled with $600 \mathrm{ml}$ DMEM supplemented with $20 \%$ FBS. Cells were incubated for $12 \mathrm{~h}$ at $37^{\circ} \mathrm{C}$ in an atmosphere containing $5 \% \mathrm{CO}_{2}$. Subsequently, the cells were fixed in $2.5 \%(\mathrm{v} / \mathrm{v})$ glutaraldehyde and stained with crystal violet. The invasive cells on the gel 
A

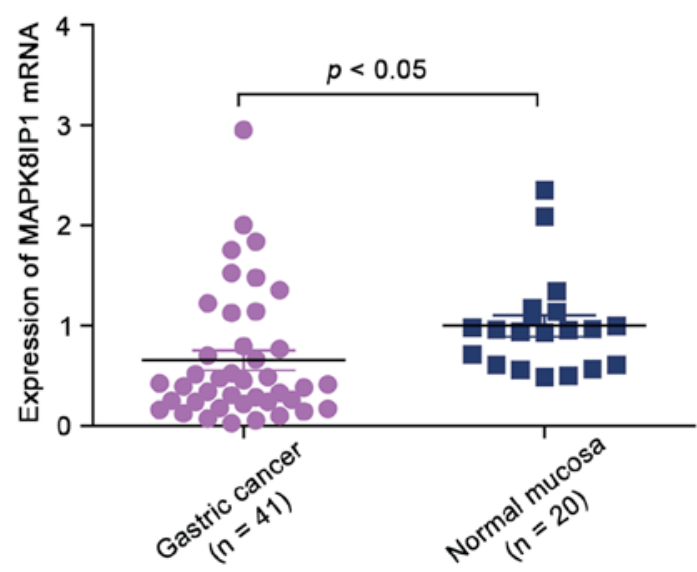

B

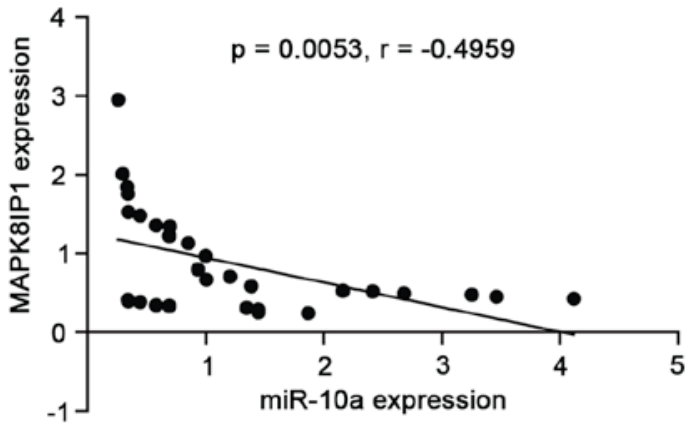

Figure 1. MAPK8IP1 was downregulated in GC specimens and inversely correlated with miR-10a expression levels. (A) Mean expression levels of MAPK8IP1 in GC specimens and normal gastric mucosa tissues. MAPK8IP1 was normalized to GAPDH. (B) A statistically significant inverse correlation was identified between miR-10a and MAPK8IP1 mRNA levels in GC specimens (Spearman's correlation analysis, $\mathrm{r}=-0.4959 ; \mathrm{P}=0.0053$ ). MAPK, mitogen-activated protein kinase; GC, gastric cancer; PTEN, phosphatase and tensin homolog.

bottom were visualized under a microscope and quantified by counting the number of cells in three randomly chosen fields at 200-fold magnification.

Vector construction and lentivirus production. Lentiviral (GV209; H1-MCS-CMV-EGFP) particles carrying a miR-10a-5p precursor and its franking control sequence were constructed by GeneChem Co., Ltd., (Shanghai, China). Lentiviral vector for cDNA delivery of MAPK8IP1 was amplified from human cDNA library and cloned into pLVTHM-GFP lentiviral vector (genome.ucsc.edu/). The packaged lentiviruses were named LVmiR10a and LV-MAPK8IP1, respectively. The empty lentiviral vector LV-con was used as a control.

Statistical analysis. SPSS 20.0 software (IBM SPSS., Armonk NY, USA) was used for statistical analysis. Data were presented as the mean \pm standard error of the mean of at least three independent experiments. Two-tailed Student's t-test was used for comparisons of two independent groups. The relationship between MAPK8IP1 and miR-10a expression was explored using Spearman's correlation analysis. $\mathrm{P}<0.05$ was considered to indicate a statistically significant difference.

\section{Results}

MAPK8IP1 was downregulated in GC specimens and inversely correlated with $\mathrm{miR}-10$ a levels. mRNA levels of MAPK8IP1 in GC specimens and normal gastric mucosa tissues were analyzed by qPCR. The results showed that the mean expression levels of MAPK8IP1 were significantly higher in normal gastric mucosa tissues than in GC specimens (Fig. 1A; P<0.05). Subsequently, MAPK8IP1 was found to correlate with miR-10a expression in the same GC specimens. As shown in Fig. 1B, a significant inverse correlation was observed (2-tailed Spearman's correlation, $r=-0.4959$; $\mathrm{P}=0.0053$ )

MAPK8IP1 is a direct target of miR-10a in GC cells. In GC, miR-10a has an important role in metastasis from primary GC to lymph nodes (23). However, the role and relevant pathways of miR-10a in GC metastasis remain largely unknown. To explore the mechanism of GC cells metastasis induced by miR-10a, whether miR-10a was able to regulate MAPK8IP1 expression in GC cells was investigated. Firstly, a luciferase reporter assay was performed to determine whether miR-10a was able to directly target the 3' UTR of MAPK8IP1 in GC cells. The target sequence of MAPK8IP1 3'-UTR [wild type (wt) 3'-UTR] or the mutant sequence [mutant (mt) 3'-UTR] was cloned into a luciferase reporter vector (Fig. 2A). MKN45 cells were subsequently transfected with wt or mt 3'-UTR vector and miR-10a mimic. The results showed a significant decrease of luciferase activity when compared with miR control (Fig. 2B, lanes 2 and 3; $\mathrm{P}<0.01$ ). Cotransfection with anti-miR-10a and wt 3'-UTR vector in MKN45 cells led to a 2.2-fold increase in luciferase activity (Fig. 2B, lanes 4 and 5 ; $\mathrm{P}<0.01)$. Moreover, the activity of $\mathrm{mt} 3$ '-UTR vector was unaffected by a simultaneous transfection with miR-10a (Fig. 2B, lanes 7 and 8).

Following this, MKN45 cells were transduced with LV-miR10a at four different multiplicity of infections (MOIs) of $0,10,50$, and 100 and the MAPK8IP1 mRNA expression levels were examined. As shown in Fig. 2C, exogenic expression of miR-10a led to a dose-dependent decrease in MAPK8IP1 mRNA expression levels. At MOI 100, the mRNA expression level of MAPK8IP1 decreased by $60-70 \%$. Moreover, inhibition of endogenous miR-10a by anti-miR-10a resulted in upregulated expression of MAPK8IP1 in MKN45 cells (Fig. 2D). These results suggested that MAPK8IP1 was a direct target of miR-10a in GC cells.

Targeting of MAPK8IP1 by miR-10a is a major mechanism for gastric cancer metastasis. In 41 patients with GC, a positive correlation between MAPK8IP1 expression and the degree of spread to regional lymph nodes (N stage) of GC was observed (Fig. 3A), suggesting the relevance of MAPK8IP1 to GC metastasis. Subsequently, MKN45 cells were transduced with LV-miR10a at four different MOIs (0, 10, 50, and 100) and a Matrigel invasion assay was used to examine the invasion ability. As shown in Fig. 3B, exogenic expression of miR-10a led to increased invasion ability in MKN45 cells. Furthermore, 
A

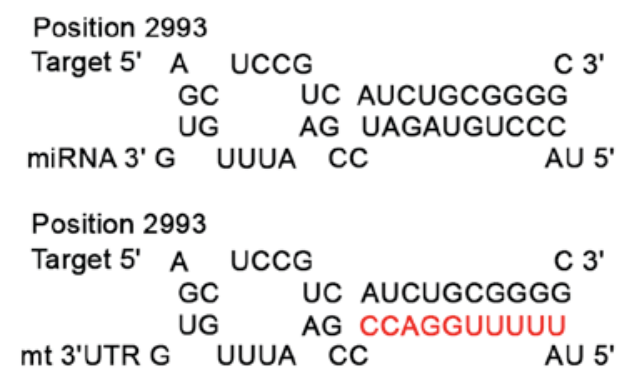

C

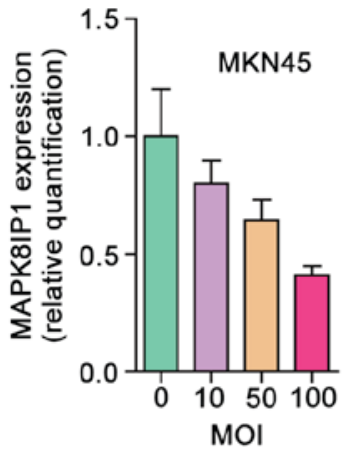

B

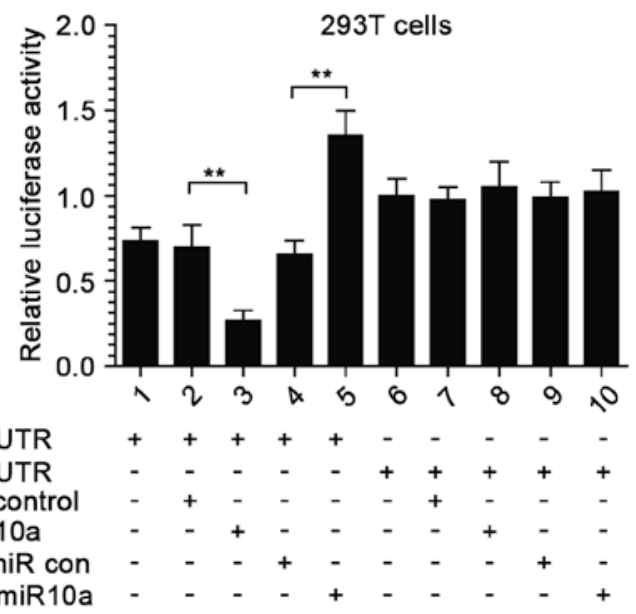

D

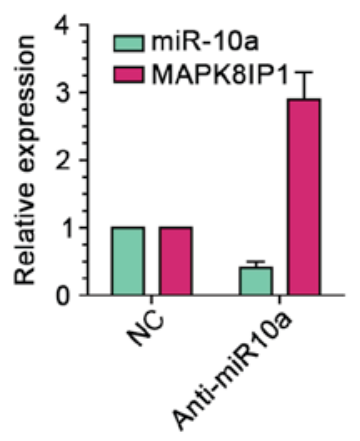

Figure 2. MAPK8IP1 was a direct target of miR-10a in GC cells. (A) Diagram of MAPK8IP1 3'UTR containing reporter constructs. (B) Luciferase reporter assays in MKN45 cells, with cotransfection of wt or mt 3'UTR and miRNA as indicated. (C) Expression mRNA level of MAPK8IP1 after LV-miR10a infection at different MOIs in MKN45 cells. (D) Expression levels of miR-10a and MAPK8IP1 after MKN45 cells were transfected with anti-miR-10a for 48 h. "P<0.05; ${ }^{* *} \mathrm{P}<0.01$. MAPK, mitogen-activated protein kinase; GC, gastric cancer; wt, wildtype; mt, mutant; MOI, multiplicity of infection.

MAPK8IP1 overexpression rescued the increased invasion of miR-10a effectors in MKN45 cells.

In a wound-healing assay, overexpression of miR-10a markedly accelerated cell migration at the edges of the scratch wound of MKN45 cells (Fig. 3C). Quantitative analyses at $24 \mathrm{~h}$ indicated a significant increment in wound closure in miR-10a overexpressing cells compared with control cells (Fig. 3D; $\mathrm{P}<0.001)$. However, MAPK8IP1 overexpression rescued the increased migration ability of miR-10a effectors in MKN45 cells. These results suggested that targeting of MAPK8IP1 by miR-10a may be a major mechanism for gastric cancer metastasis.

Cell migration regulators contribute to the metastasis effect induced by miR-10a. Cell-cell junction and PI3K/Akt pathways are involved in the regulation of cell migration progression and are frequently over activated in $\operatorname{GC}(25,26)$. To elucidate whether these regulators were involved in the metastasis effect of miR-10a, the mRNA levels of eight cell migration regulators were anayzed in MKN45 cells by qPCR, including $\beta$-catenin, Snail, fibronectin, Vimentin, PTEN, Akt, $\mathrm{N}$-cadherin and E-cadherin. The results demonstrated that the levels of $\beta$-catenin, Snail, fibronectin, vimentin and $\mathrm{N}$-cadherin were increased by $>2.5$-fold, whereas the mRNA levels of PTEN and E-cadherin were decreased after miR-10a overexpression. By contrast, anti-miR-10a treatment produced contrasting results (Fig. 4).

\section{Discussion}

As demonstrated in previous studies, miRNA are associated with numerous cellular processes, including proliferation, differentiation and apoptosis, and they have an important role in the pathogenesis of cancer $(27,28)$. For example, a previous study by our group demonstrated that EBV-miRBART7-3p was a viral oncomir that is highly overexpressed in NPC tissues, which promotes NPC tumorigenesis (29). Gastric cancer is caused by the interaction of environmental and genetic factors (30). It has been reported that miR-10a is overexpressed in human pancreatic cancer and involved in its invasiveness; retinoic acid receptor antagonists inhibit miR-10a expression and block metastatic behavior of pancreatic cancer $(20,21)$. In a mouse mammary tumor model, therapeutic silencing of miR-10b inhibited metastasis (22). In GC, miR-10a has an important role in metastasis from primary GC to lymph nodes (23). However, the role and relevant pathways of miR-10a in GC metastasis remain largely unknown.

MAPK signaling pathway activation correlates with human cancer progression and metastasis (7). MAPK8IP1 acts as a negative regulator of MAPK activity (31). To explore the mechanism of GC cells metastasis induced by miR-10a, the present study investigated whether miR-10a was able to regulate MAPK8IP1 expression in GC cells. The present findings found that the mean expression level of MAPK8IP1 was significantly elevated in normal gastric mucosa tissues, 
A

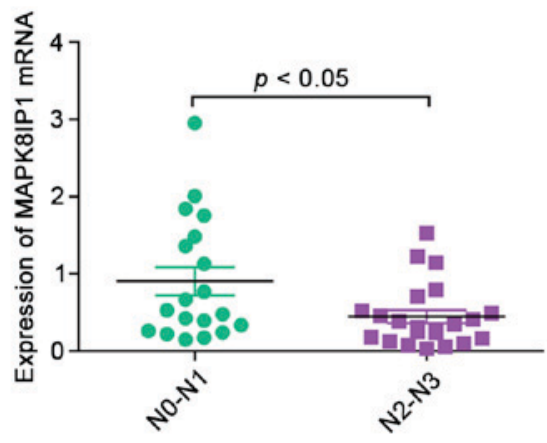

C

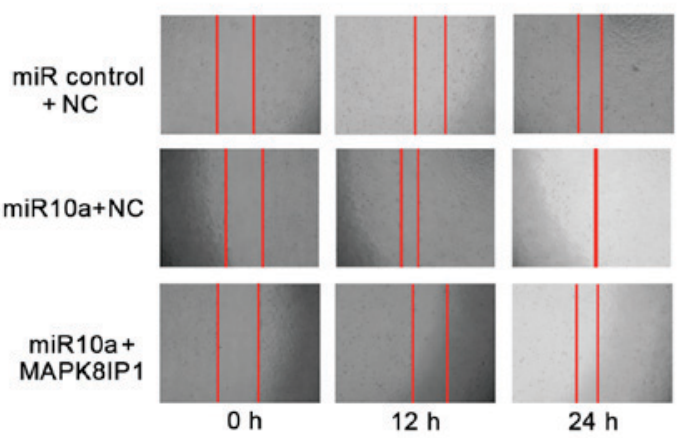

B

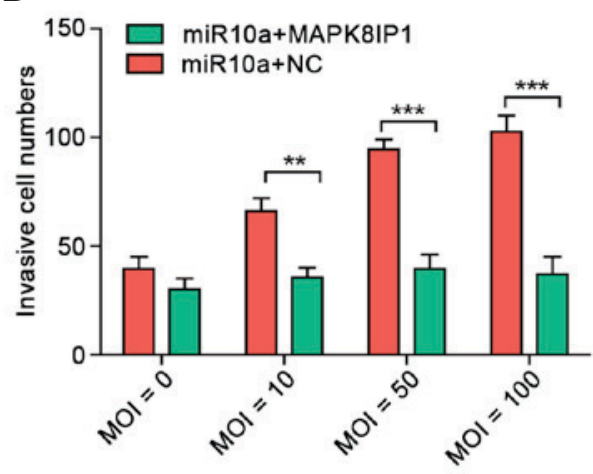

D

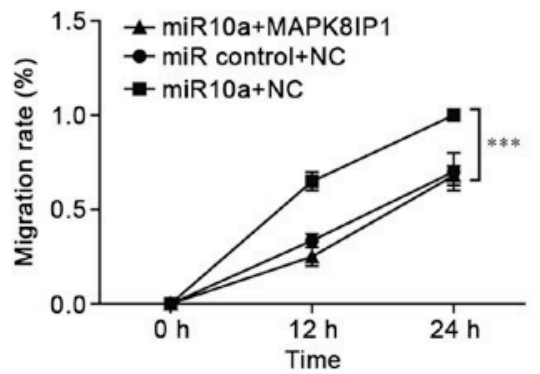

Figure 3. Targeting of MAPK8IP1 by miR-10a-5p is a major mechanism for gastric cancer metastasis. (A) MAPK8IP1 mRNA expression levels normalized to GAPDH were detected by quantitative polymerase chain reaction in GC samples with $\mathrm{N}$ stage disease. Data are presented as the mean \pm standard error of the mean. (B) Cell invasion assay showed increased invasion from cells after LV-miR10a infection at different MOIs in MKN45 cells. MAPK8IP1 overexpression rescued the increased invasion activity of miR-10a effectors in MKN45 cells. (C) Wound-healing assay showed MKN45 cells stably expressing the miR10a at 0,12 and $24 \mathrm{~h}$ after wounding. (D) Relative migration ability at 0,12 and $24 \mathrm{~h}$. MAPK8IP1 overexpression rescued the increased migration ability of miR-10a effectors in MKN45 cells. ${ }^{* *} \mathrm{P}<0.01 ;{ }^{* * *} \mathrm{P}<0.001$. MAPK, mitogen-activated protein kinase; GC, gastric cancer; MOI, multiplicity of infection.

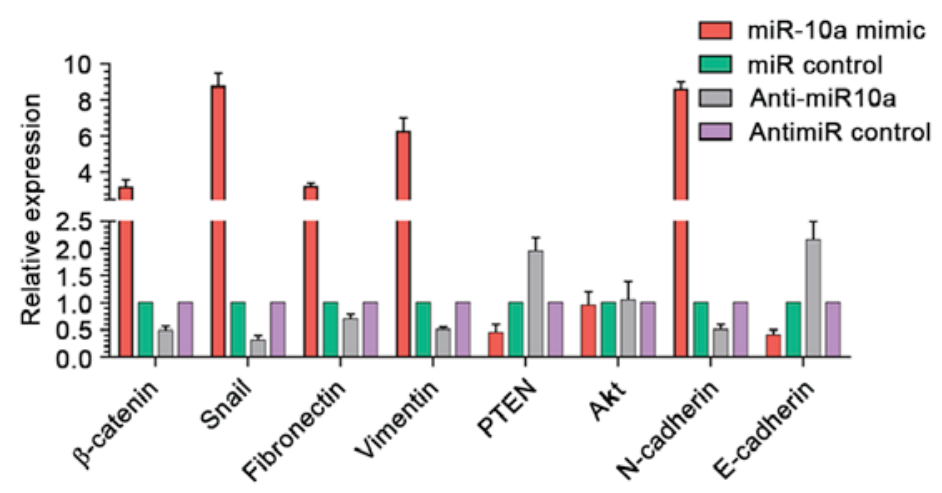

Figure 4. Cell migration regulators contributed to the metastasis effect induced by miR-10a. Deregulated expression of eight cell migration regulators in MKN45 cells after miR-10a mimic or inhibitor transfection. MAPK, mitogen-activated protein kinase; PTEN, phosphatase and tensin homolog.

as compared with GC specimens. Furthermore, it was determined that MAPK8IP1 correlated with miR-10a expression levels in the same GC specimens. Inverse correlation was observed between MAPK8IP1 and miR-10a mRNA expression levels. These results suggested that miR-10a may regulate MAPK8IP1 expression in GC cells.

Luciferase reporter assay and qPCR results suggested that MAPK8IP1 was a direct target of miR-10a in GC cells. In 41 patients with GC, a positive correlation was observed between MAPK8IP1 expression and the degree of spread to regional lymph nodes ( $\mathrm{N}$ stage) of $\mathrm{GC}$, suggesting the relevance of MAPK8IP1 to GC metastasis. Exogenic expression of
miR-10a led to increased invasion ability of MKN45 cells. The present results also showed that MAPK8IP1 overexpression rescued the increased invasion ability of miR-10a effectors in MKN45 cells. In a wound-healing assay, overexpression of miR-10a markedly accelerated cell migration at the edges of the scratch wound of MKN45 cells. However, MAPK8IP1 overexpression rescued the increased migration ability of miR-10a effectors in MKN45 cells. Taken together, these results suggested that targeting of MAPK8IP1 by miR-10a may be a major mechanism for gastric cancer metastasis.

It is well known that a typical miRNA has $~ 100$ target sites and forms a regulatory network (32). PTEN loss and MAPK 
activation cooperate to promote epithelial-to-mesenchymal transition and metastasis in prostate cancer stem cells (7). Cell-cell junction and PI3K/Akt pathways are involved in the regulation of cell migration progression, and are frequently overactivated in GC (33-35). To elucidate whether these regulators were associated with the metastasis effect of miR-10a, the mRNA levels of eight cell migration regulators were examined in MKN45 cells. The present results demonstrated that the levels of $\beta$-catenin, Snail, fibronectin, vimentin and $\mathrm{N}$-cadherin were increased by $>2.5$-fold, whereas the mRNA expression levels of PTEN and E-cadherin were decreased after miR-10a overexpression. By contrast, anti-miR-10a treatment produced contrasting results.

In conclusion, the present study indicated that miR-10a-5p directly targets MAPK8IP1, which is a negative regulator of MAPK activity, and thus may be a major mechanism for gastric cancer metastasis. These findings suggested that miR-10a may be a potential target for the treatment of GC in the future.

\section{References}

1. Jemal A, Bray F, Center MM, Ferlay J, Ward E and Forman D: Global cancer statistics. CA Cancer J Clin 61: 69-90, 2011.

2. Wakamatsu Y, Sakamoto N, Oo HZ, Naito Y, Uraoka N, Anami K, Sentani K, Oue N and Yasui W: Expression of cancer stem cell markers ALDH1, CD44 and CD133 in primary tumor and lymph node metastasis of gastric cancer. Pathol Int 62: 112-119, 2012.

3. Hsu KW, Hsieh RH, Huang KH, Fen-Yau Li A, Chi CW, Wang TY, Tseng MJ, Wu KJ and Yeh TS: Activation of the Notch1/STAT3/Twist signaling axis promotes gastric cancer progression. Carcinogenesis 33: 1459-1467, 2012.

4. Takano Y, Kato Y, Masuda M, Ohshima Y and Okayasu I: Cyclin D2, but not cyclin D1, overexpression closely correlates with gastric cancer progression and prognosis. J Pathol 189: 194-200, 1999.

5. Maruyama K, Gunvén P, Okabayashi K, Sasako M and Kinoshita T: Lymph node metastases of gastric cancer. General pattern in 1931 patients. Ann Surg 210: 596-602, 1989.

6. Qu JL, Qu XJ, Zhao MF, Teng YE, Zhang Y, Hou KZ, Jiang YH, Yang XH and Liu YP: Gastric cancer exosomes promote tumour cell proliferation through PI3K/Akt and MAPK/ERK activation. Dig Liver Dis 41: 875-880, 2009.

7. Mulholland DJ, Kobayashi N, Ruscetti M, Zhi A, Tran LM, Huang J, Gleave $M$ and Wu H: Pten loss and RAS/MAPK activation cooperate to promote EMT and metastasis initiated from prostate cancer stem/progenitor cells. Cancer Res 72: 1878-1889, 2012.

8. Davis RJ: Signal transduction by the JNK group of MAP kinases. Cell 103: 239-252, 2000.

9. Thompson NA, Haefliger JA and Senn A, Tawadros T, Magara F, Ledermann B, Nicod P and Waeber G: Islet-brain1/JNK-interacting protein-1 is required for early embryogenesis in mice. J Biol Chem 276: 27745-27748, 2001.

10. Crew KD and Neugut AI: Epidemiology of gastric cancer. World J Gastroenterol 12: 354-362, 2006.

11. Bartel DP: MicroRNAs: Target recognition and regulatory functions. Cell 136: 215-233, 2009.

12. Esquela-Kerscher A and Slack FJ: Oncomirs-microRNAs with a role in cancer. Nat Rev Cancer 6: 259-269, 2006.

13. Cao M, Seike M, Soeno C, Mizutani H, Kitamura K, Minegishi Y, Noro R, Yoshimura A, Cai L and Gemma A: MiR-23a regulates TGF- $\beta$-induced epithelial-mesenchymal transition by targeting E-cadherin in lung cancer cells. Int J Oncol 41: 869-875, 2012.

14. Pacurari M, Addison JB, Bondalapati N, Wan YW, Luo D, Qian Y, Castranova V, Ivanov AV and Guo NL: The microRNA-200 family targets multiple non-small cell lung cancer prognostic markers in H1299 cells and BEAS-2B cells. Int J Oncol 43: $548-560,2013$

15. Verdoodt B, Neid M, Vogt M, Kuhn V, Liffers ST, Palisaar RJ, Noldus J, Tannapfel A and Mirmohammadsadegh A: MicroRNA-205, a novel regulator of the anti-apoptotic protein $\mathrm{Bcl} 2$, is downregulated in prostate cancer. Int J Oncol 43 : 307-314, 2013.
16. Wang P, Zou F, Zhang X, Li H, Dulak A, Tomko RJ Jr, Lazo JS, Wang $\mathrm{Z}$, Zhang $\mathrm{L}$ and $\mathrm{Yu}$ J: microRNA-21 negatively regulates Cdc25A and cell cycle progression in colon cancer cells. Cancer Res 69: 8157-8165, 2009.

17. Calin GA, Ferracin M, Cimmino A, Di Leva G, Shimizu M, Wojcik SE, Iorio MV, Visone R, Sever NI, Fabbri M, et al: A MicroRNA signature associated with prognosis and progression in chronic lymphocytic leukemia. N Engl J Med 353: 1793-1801, 2005.

18. Veerla S, Lindgren D, Kvist A, Frigyesi A, Staaf J, Persson H, Liedberg F, Chebil G, Gudjonsson S, Borg A, et al: MiRNA expression in urothelial carcinomas: Important roles of miR-10a, miR-222, miR-125b, miR-7 and miR-452 for tumor stage and metastasis, and frequent homozygous losses of miR-31. Int J Cancer 124: 2236-2242, 2009.

19. Ujifuku K, Mitsutake N, Takakura S, Matsuse M, Saenko V, Suzuki K, Hayashi K, Matsuo T, Kamada K, Nagata I and Yamashita S: miR-195, miR-455-3p and miR-10a (*) are implicated in acquired temozolomide resistance in glioblastoma multiforme cells. Cancer Lett 296: 241-248, 2010.

20. Ohuchida K, Mizumoto K, Lin C, Yamaguchi H, Ohtsuka T, Sato N, Toma H, Nakamura M, Nagai E, Hashizume $M$ and Tanaka M: MicroRNA-10a is overexpressed in human pancreatic cancer and involved in its invasiveness partially via suppression of the HOXA1 gene. Ann Surg Oncol 19: 2394-2402, 2012.

21. Weiss FU, Marques IJ, Woltering JM, Vlecken DH, Aghdassi A, Partecke LI, Heidecke CD, Lerch MM and Bagowski CP: Retinoic acid receptor antagonists inhibit miR-10a expression and block metastatic behavior of pancreatic cancer. Gastroenterology 137: 2136-2145.e1-7, 2009.

22. Ma L, Reinhardt F, Pan E, Soutschek J, Bhat B, Marcusson EG, Teruya-Feldstein J, Bell GW and Weinberg RA: Therapeutic silencing of miR-10b inhibits metastasis in a mouse mammary tumor model. Nat Biotechnol 28: 341-347, 2010.

23. Chen W, Tang Z, Sun Y, Zhang Y, Wang X, Shen Z, Liu F and Qin X: miRNA expression profile in primary gastric cancers and paired lymph node metastases indicates that miR-10a plays a role in metastasis from primary gastric cancer to lymph nodes. Exp Ther Med 3: 351-356, 2012.

24. Novák J and Fabian P: Comments on the TNM classification of malignant tumours - 7th edition. Klin Onkol 24: 149-150, 2011 (In Czech).

25. Brabletz T, Jung A, Spaderna S, Hlubek F and Kirchner T: Opinion: migrating cancer stem cells - an integrated concept of malignant tumour progression. Nat Rev Cancer 5: 744-749, 2005.

26. Liu J, Zhang Y and Xu R, Du J, Hu Z, Yang L, Chen Y, Zhu Y and Gu L: PI3K/Akt-dependent phosphorylation of GSK3 $\beta$ and activation of RhoA regulate Wnt5a-induced gastric cancer cell migration. Cell Signal 25: 447-456, 2013.

27. Zhang Z, Liu S, Shi R and Zhao G: miR-27 promotes human gastric cancer cell metastasis by inducing epithelial-to-mesenchymal transition. Cancer Genet 204: 486-491, 2011.

28. Li X, Zhang Y, Zhang H, Liu X, Gong T, Li M, Sun L, Ji G, Shi Y, Han Z, et al: miRNA-223 promotes gastric cancer invasion and metastasis by targeting tumor suppressor EPB41L3. Mol Cancer Res 9: 824-833, 2011.

29. Cai L, Li J, Zhang X, Lu Y, Wang J, Lyu X, Chen Y, Liu J, Cai H, Wang Y and Li X: Gold nano-particles (AuNPs) carrying anti-EBV-miR-BART7-3p inhibit growth of EBV-positive nasopharyngeal carcinoma. Oncotarget 6: 7838-7850, 2015.

30. Doll R and Peto R: The causes of cancer: Quantitative estimates of avoidable risks of cancer in the United States today. J Natl Cancer Inst 66: 1191-1308, 1981.

31. Harding TC, Xue L, Bienemann A, Haywood D, Dickens M, Tolkovsky AM and Uney JB: Inhibition of JNK by overexpression of the JNL binding domain of MAPK8IP1 prevents apoptosis in sympathetic neurons. J Biol Chem 276: 4531-4534, 2001.

32. Saunders MA, Liang H and Li WH: Human polymorphism at microRNAs and microRNA target sites. Proc Natl Acad Sci USA 104: 3300-3305, 2007.

33. Li D, Qu X, Hou K, Zhang Y, Dong Q, Teng Y, Zhang J and Liu Y: PI3K/Akt is involved in bufalin-induced apoptosis in gastric cancer cells. Anticancer Drugs 20: 59-64, 2009.

34. Xie X, Tang B, Zhou J, Gao Q and Zhang P: Inhibition of the PI3K/Akt pathway increases the chemosensitivity of gastric cancer to vincristine. Oncol Rep 30: 773-782, 2013.

35. Liu J, Liu Q, Wan Y, Zhao Z, Yu H, Luo H and Tang Z: Osteopontin promotes the progression of gastric cancer through the NF- $\mathrm{KB}$ pathway regulated by the MAPK and PI3K. Int $\mathrm{J}$ Oncol 45: 282-290, 2014. 